\title{
BMJ Open Do doctors in dispensing practices with a financial conflict of interest prescribe more expensive drugs? A cross-sectional analysis of English primary care prescribing data
}

Ben Goldacre, ${ }^{1}$ Carl Reynolds, ${ }^{2}$ Anna Powell-Smith, ${ }^{1}$ Alex J Walker, ${ }^{1}$ Tom A Yates, ${ }^{3}$ Richard Croker, ${ }^{1}$ Liam Smeeth ${ }^{4}$

To cite: Goldacre B,

Reynolds C, Powell-Smith A, et al. Do doctors in dispensing practices with a financial conflict of interest prescribe more expensive drugs? A cross-sectional analysis of English primary care prescribing data. BMJ Open 2019;9:e026886. doi:10.1136/ bmjopen-2018-026886

- Prepublication history for this paper is available online. To view these files, please visit the journal online (http://dx.doi org/10.1136/bmjopen-2018026886).

Received 24 September 2018 Revised 1 November 2018 Accepted 22 November 2018

Check for updates

(C) Author(s) (or their employer(s)) 2019. Re-use permitted under CC BY-NC. No commercial re-use. See rights and permissions. Published by BMJ.

For numbered affiliations see end of article.

Correspondence to

Dr Ben Goldacre;

ben.goldacre@phc.ox.ac.uk

\section{ABSTRACT}

Objectives Approximately one in eight practices in primary care in England are 'dispensing practices' with an in-house dispensary providing medication directly to patients. These practices can generate additional income by negotiating lower prices on higher cost drugs, while being reimbursed at a standard rate. They, therefore, have a potential financial conflict of interest around prescribing choices. We aimed to determine whether dispensing practices are more likely to prescribe high-cost options for four commonly prescribed classes of drug where there is no evidence of superiority for high-cost options.

Design A list was generated of drugs with high acquisition costs that were no more clinically effective than those with the lowest acquisition costs, for all four classes of drug examined. Data were obtained prescribing of statins, proton pump inhibitors (PPIs), angiotensin receptor blockers (ARBs) and ACE inhibitors (ACEis). Logistic regression was used to calculate $\mathrm{ORs}$ for prescribing highcost options in dispensing practices, adjusting for Index of Multiple Deprivation score, practice list size and the number of doctors at each practice.

Setting English primary care.

Participants All general practices in England.

Main outcome measures Mean cost per dose was calculated separately for dispensing and non-dispensing practices. Dispensing practices can vary in the number of patients they dispense to; we, therefore, additionally compared practices with no dispensing patients, low, medium and high proportions of dispensing patients. Total cost savings were modelled by applying the mean cost per dose from non-dispensing practices to the number of doses prescribed in dispensing practices.

Results Dispensing practices were more likely to prescribe high-cost drugs across all classes: statins adjusted OR 1.51 (95\% $\mathrm{Cl} 1.49$ to $1.53, \mathrm{p}<0.0001)$, PPIs OR 1.11 (95\% Cl 1.09 to 1.13, p<0.0001), ACEi OR 2.58 (95\% Cl 2.46 to $2.70, \mathrm{p}<0.0001)$, ARB OR 5.11 (95\% Cl 5.02 to $5.20, p<0.0001)$. Mean cost per dose in pence was higher in dispensing practices (statins 7.44 vs 6.27 , PPIs 5.57 vs 5.46 , ACEi 4.30 vs 4.24 , ARB 11.09 vs 8.19 ). For all drug classes, the more dispensing patients a practice had, the more likely it was to issue a prescription for a high-cost option. Total cost savings in England available
Strengths and limitations of this study

- We found a substantial effect size, which was present across four broad categories of high-cost prescribing.

- We were able to measure prescribing for the whole of England, eliminating selection bias.

- We were able to use demographic data to adjust for potential confounding factors, such as practice list size and deprivation.

- Though we prespecified the list of high-cost and low-cost options created for the logistic regression, we feel these choices reflect the high-cost and lowcost options available. This list is available online.

- We were unable to determine a causal relationship, given the cross-sectional design of the study.

from all four classes are $£ 628875$ per month or $£ 7546$ 502 per year.

Conclusions Doctors in dispensing practices are more likely to prescribe higher cost drugs. This is the largest study ever conducted on dispensing practices, and the first contemporary research suggesting some UK doctors respond to a financial conflict of interest in treatment decisions. The reimbursement system for dispensing practices may generate unintended consequences. Robust routine audit of practices prescribing higher volumes of unnecessarily expensive drugs may help reduce costs.

\section{BACKGROUND}

Approximately one in eight practices in English National Health Service (NHS) primary care are 'dispensing practices', with an in-house dispensary. These practices are generally found in rural areas that have fewer pharmacies, and help provide convenient access to medicines for patients. However, doctors working in dispensing practices have a potential financial conflict of interest around their prescribing decisions, because 
they have the opportunity to earn additional practice revenue by prescribing higher cost drugs. This arises because the dispensary arm of such practices can purchase high-cost branded drugs at a discount, when procuring large quantities of commonly used treatments, but they continue to receive reimbursement from the NHS at a flat rate which is pegged to the standard non-discounted cost of a drug. ${ }^{1}$ Drugs with lower acquisition costs present less opportunity for profit. When a general practitioner (GP) prescribes a drug generically reimbursement is usually based on the Drug Tariff generic price, although the dispensing contractor can supply either a generic or branded product against that prescription. However, when the prescription is written for a branded preparation, the dispensing contractor must supply that brand, and is reimbursed accordingly. There is no opportunity for generic substitution in the NHS in England.

There is an extensive literature suggesting that, like other people, the choices of doctors can be affected by their financial interests. ${ }^{2-4}$ A 2009 systematic review examined whether doctors with a dispensing role exhibited different prescribing behaviour in a wide range of settings including Zimbabwe, South Korea, Taiwan and the UK in the 1990s. ${ }^{5}$ The review found studies measuring a range of outcomes. Many of these studies refer to outdated or unusual health system configurations, such as settings with minimal controls around prescribed drugs, and the largest studies compared only a few tens of practices, a few hundred patient records or a few tens of thousands of prescriptions.

We set out to examine whether NHS doctors in English dispensing practices have different prescribing behaviour to non-dispensing practices. We used modern computational methods on a very large quantity of highly granular contemporary national data. Our objectives were to establish whether dispensing practices were more likely to prescribe more expensive drugs in place of cheaper and equally effective drugs, using fair comparisons where there were no grounds to expect a difference between rural and urban areas. We focused on commonly prescribed treatments where the difference in cost was large (rather than prescriptions of very high-cost items that are infrequently prescribed) because this is where the potential conflict of interest is greatest, as discounted purchases on higher cost drugs can be arranged by dispensing practices when purchasing larger quantities of drugs.

\section{METHODS}

\section{Data preparation}

Prescribing data for each practice were obtained from the Health and Social Care Information Centre (HSCIC) NHS England Primary Care Prescribing dataset ${ }^{6}$ for all prescriptions dispensed by all NHS dispensing contractors, including pharmacies and dispensing practices, submitted for payment to the NHS Business Services Authority (NHSBSA) for January 2015. The data were imported into Google BigQuery. ${ }^{7}$ Data were extracted at 'presentation' level, which in the context of prescribing data means the actual product prescribed by the doctor, including the identity of the specific branded or "branded generic' product (where specified) rather than simply the chemical name. Prescribing costs for each product in each practice were calculated using the 'actual cost' field in the HSCIC data, which is the cost to the NHS. The identity of each practice's clinical commissioning group (CCG) was also imported from this dataset.

A list of dispensing practices covering January 2015 was downloaded from the NHSBSA website ${ }^{8}$ and matched onto the prescribing data. This dataset gives the number of dispensing and non-dispensing patients in each GP practice. Practices are not only 'dispensing' or 'non-dispensing' practices: each dispensing practice may serve a range of patients, with some 'dispensing patients' who live in areas without adequate pharmacy provision and receive both medical and dispensing services; and some 'non-dispensing patients' who receive only medical services. For each practice, the proportion of dispensing patients was calculated and converted into both a binary variable (no dispensing patients, any dispensing patients) and an ordinal categorical variable with arbitrary prespecified cut points at $0.000001 \%, 35 \%$ and $70 \%$. These data also include a binary 'GP practice' field. This was used to drop all non-standard practices (including out of hours services, community health services, prisons and homeless clinics) from the dataset, leaving only data from standard GP settings.

We also imported demographic data on Index of Multiple Deprivation (IMD) score (from Public Health England), practice list size (from NHS Digital) and the number of doctors at each practice (from NHS Digital), to be used to adjust for confounding in multivariable models.

A two-way table was created for each analysis, where each row contained data on a single practice with columns for practice identification code and name; CCG identification code; the number of dispensing patients and the total number of patients; dispensing status; ordinal dispensing status; total items dispensed, total quantity dispensed and total cost for the high-cost drugs; and total items dispensed, total quantity dispensed and total cost for the lower cost drugs. In this dataset, an 'item' is a presentation appearing on a prescription, while 'quantity' is the number of doses issued.

\section{High-cost and low-cost drugs}

We examined prescribing data on statins, proton pump inhibitors (PPIs), ACE inhibitors (ACEis) and angiotensin receptor blockers (ARBs) as these are the four most commonly prescribed classes of drugs by prescription items from NHS England prescribing data where there is clear guidance that higher cost items are no more effective than lower cost items. Within each of these four classes, we identified options with a high acquisition cost which are considered to be as effective as those with the lowest acquisition cost, ${ }^{9-12}$ in discussion with colleagues 
Table 1 List of higher and lower cost options in each class

\begin{tabular}{|c|c|c|}
\hline Class & Higher cost options & Lower cost options \\
\hline Statins & $\begin{array}{l}\text { Rosuvastatin (all), Crestor, Atorvastatin } 30 \mathrm{mg} \text { and } \\
60 \mathrm{mg} \text {, Lipitor, Fluvastatin } 80 \mathrm{mg} \mathrm{M} / \mathrm{R} \text { tabs, Lescol } \\
\text { capsules, Luvinsta XL, Dorisin XL, Lipostat, Zocor. }\end{array}$ & $\begin{array}{l}\text { Atorvastatin } 10 / 20 / 40 / 80 \mathrm{mg} \text { tabs, Fluvastatin caps, } \\
\text { Pravastatin, Simvastatin, Simvador (low-cost branded } \\
\text { option). }\end{array}$ \\
\hline $\begin{array}{l}\text { Proton pump } \\
\text { inhibitor }\end{array}$ & $\begin{array}{l}\text { Nexium, Zoton Cap } 30 \mathrm{mg} \text { E/C Gran, Omeprazole } \\
\text { E/C tabs, Losec caps, Losec dispersible, Omeran, } \\
\text { Zanprol, Mezzopram, Protium, Pantoloc, Pariet. }\end{array}$ & $\begin{array}{l}\text { Esomeprazole, Emozul, Lansoprazole, Zoton FasTab, } \\
\text { Omeprazole caps, Mepradec Caps, Pantoprazole, } \\
\text { Rabeprazole. }\end{array}$ \\
\hline $\begin{array}{l}\text { Angiotensin } \\
\text { receptor blocker }\end{array}$ & $\begin{array}{l}\text { Azilsartan, Edarbi, Olmesartan, Olmetec, Amias, } \\
\text { Aprovel, Cozaar, Micardis, Tolura, Diovan, } \\
\text { Eprosartan, Teveten. }\end{array}$ & $\begin{array}{l}\text { Candesartan cilexet, Irbesartan, Losartan, Telmisartan, } \\
\text { Valsartan. }\end{array}$ \\
\hline
\end{tabular}

in clinical pharmacology, medicines optimisation and evidence-based medicine. This included not just branded versions of generic drugs (such as Lipitor in place of generic atorvastatin), but also different drugs in the same class that are widely held to be equally effective (such as rosuvastatin in place of atorvastatin). These are known as 'generic substitutions' and 'therapeutic substitutions', respectively. ${ }^{13}$ The lower cost options are not held to be universally clinically preferable, with an ideal prescribing rate for the expensive options of zero, because some individual patients may benefit from a different choice of drug within a class on the grounds of idiosyncratic side effects or treatment response. However, there are no a priori grounds to believe that such patients would be differentially distributed among dispensing and non-dispensing practices. By taking the proportion of prescriptions for each class, which were for high-cost options, we, therefore, controlled for a patient need for the total volume of prescribing for each clinical indication.

The lists of drugs and drug presentations (ie, brands) coded as high-cost or low-cost are in table 1, and the full British National Formulary and HSCIC prescribing data code lists are available on GitHub ${ }^{14}$ to facilitate reproducibility. This list was generated with a senior pharmacist (RC) prior to conducting the low-cost versus high-cost analysis. Drugs and presentations were manually coded as low and high cost, because it is incorrect to assume that generic products are always low cost, and branded products high-cost: when a chemical comes out of patent, the price of the branded item often falls in line with cheaper generic entrants to the market; while generic options may be manufactured for drugs before they come out of patent (under agreement from the patent holder) at similarly high prices to the branded product. Where a drug was out of patent, and a branded version continued to be available alongside generic options, but its price was comparable to the generic options, then that low-cost branded version was included in the low-cost list. Where a branded option continued to be available after patent expiry but was more than three times the cost of the generic option, it was counted as a higher cost branded option. These high-cost branded off-patent drugs are specifically identified in table 1 by brand name alongside the drugs that remain entirely under patent. (For clarity: perindopril arginine is a branded product currently under patent, while perindopril erbumine is now off-patent and available in low-cost generic formulations).

\section{Data analysis}

Data were imported into Stata V.14 $4^{15}$ for analysis by logistic regression. Although the NHS England dataset contains only aggregated numbers of prescriptions for each practice, each prescription in each practice in each class was analysed as a single prescribing choice for each patientto either give a high-cost or low-cost drug-as it is highly unlikely that any patients were prescribed two members of the same class of drug simultaneously. For each class of drug, we calculated ORs for prescribing a high-cost option in dispensing and non-dispensing practices using logistic regression. We then repeated this analysis using the ordinal categorical variable for dispensing status to assess whether there was a 'dose-response' relationship between the proportion of dispensing patients in a practice and the odds of prescribing a high-cost option. For both logistic regression models, above, we also created multivariable models, adjusting for IMDs, practice list size and the number of doctors in each practice.

For each class of drug, the mean cost per prescription was calculated, separately for dispensing practices and non-dispensing practices, by aggregating the cost of all prescriptions issued and dividing this by the number of doses issued. This was calculated by dose, rather than by prescription, as the number of doses per prescription can vary. This was repeated for each ordinal category of dispensing practices. Since only $13 \%$ of all practices in England are dispensing practices, we also calculated the proportion of dispensing practices in the top 10 and top 100 highest prescribers of high-cost options, to 
explore whether dispensing practices were more likely to be among the highest prescribers of high-cost options nationally.

Lastly, we modelled cost savings available in England if dispensing practices were to prescribe drugs with the same mean cost per dose as non-dispensing practices. The mean cost per dose of non-dispensing practices was multiplied by the total number of doses prescribed in each dispensing practice, to calculate the modelled total cost for that class of drugs, and this was subtracted from the actual total cost, for all dispensing practices.

\section{Patient and public involvement}

No patients were involved in setting the research question or the outcome measures, nor were they involved in the design or conduct of the study. No patients were asked to advise on the interpretation or writing up of results. There are no plans to disseminate the results of the research to study participants.

\section{RESULTS}

All data were imported successfully. Only standard GP practices were analysed, therefore, 2863 non-standard prescribing settings in the same dataset were dropped (this included out of hours services, community health services, prisons and homeless clinics). Data for 7836 practices with a mean patient list of 7258 people were analysed in 211 CCGs, each containing between 1 and 123 practices. In total, the data for the month covered 15 060963 items (with a total cost of $£ 30862$ 027). The odds ratios for prescriptions from the high-cost or low-cost list are presented in table 2, alongside the percentage of all prescriptions that were for high-cost options in dispensing and non-dispensing practices, the mean price per dose for prescriptions issued in dispensing and non-dispensing practices, and the total number of prescriptions issued in England. From this, it can be seen that dispensing practices are significantly more likely to prescribe drugs from the list of higher cost products across all four categories: statins OR 1.66 (95\% CI 1.64 to $1.68, \mathrm{p}<0.0001$ ), PPI OR 1.14 (95\% CI 1.12 to $1.17, \mathrm{p}<0.0001)$, ACEi OR 2.42 (95\% CI 2.32 to 2.52, $\mathrm{p}<0.0001$ ), ARB OR 4.79 (95\% CI 4.72 to $4.87, \mathrm{p}<0.0001)$. Similar odds ratios are observed after adjusting for IMD, practice list size and number of GPs (table 2).

The OR for prescription of a high-cost option by an increasing proportion of dispensing patients is presented in table 3. From this, it can be seen that there is a consistent pattern for higher odds of high-cost prescribing the more dispensing patients a practice has, across all four classes of drug. Again, there is little difference in ORs between the univariable and multivariable models. A similar pattern is seen for the mean cost per dose in table 4.

Dispensing practices make up only $13 \%$ of all practices overall. Table 5 shows the proportion of dispensing

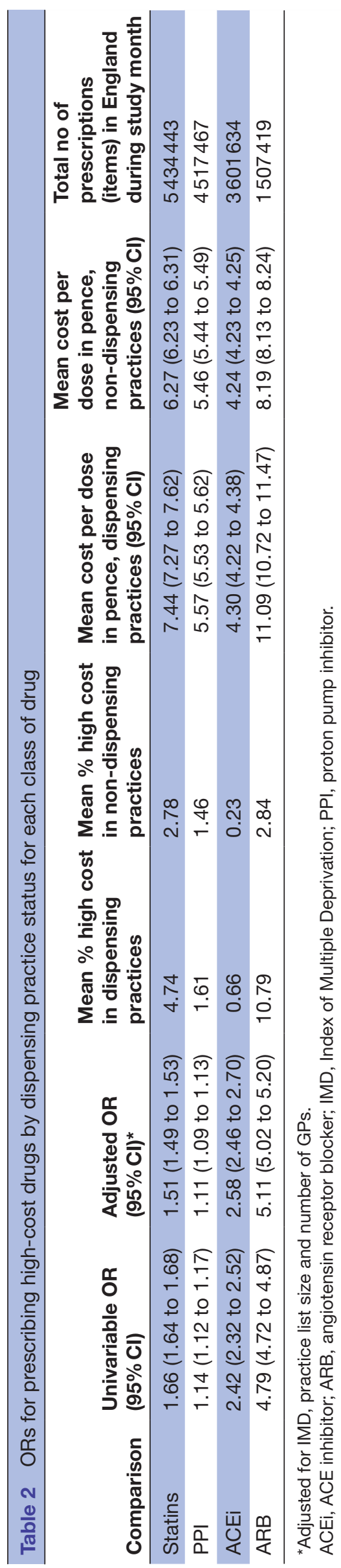


Table 3 ORs for prescribing high-cost drugs by category of dispensing practice

\begin{tabular}{|c|c|c|c|c|c|}
\hline \multirow[b]{2}{*}{ Drug } & \multirow{2}{*}{$\begin{array}{l}\text { Proportion of } \\
\text { dispensing patients }\end{array}$} & \multicolumn{2}{|l|}{ Univariable } & \multicolumn{2}{|c|}{$\begin{array}{l}\text { Deprivation, practice list size } \\
\text { and no of GPs }\end{array}$} \\
\hline & & OR & $95 \% \mathrm{Cl}$ & OR & $95 \% \mathrm{Cl}$ \\
\hline \multirow{2}{*}{ Statins } & $>0 \%-35 \%$ & 1.46 & (1.43 to 1.48$)$ & 1.35 & (1.32 to 1.37 ) \\
\hline & $35 \%-70 \%$ & 1.79 & (1.76 to 1.82$)$ & 1.62 & (1.59 to 1.65$)$ \\
\hline \multirow{3}{*}{ Proton pump inhibitor } & $>0 \%-35 \%$ & 1.11 & (1.08 to 1.14$)$ & 1.08 & (1.05 to 1.11$)$ \\
\hline & $35 \%-70 \%$ & 1.12 & (1.08 to 1.15$)$ & 1.08 & (1.05 to 1.12$)$ \\
\hline & $70 \%-100 \%$ & 1.31 & (1.26 to 1.37 ) & 1.27 & (1.21 to 1.32$)$ \\
\hline ACE inhibitor & 0 & Reference & & Reference & \\
\hline \multirow[t]{4}{*}{ Angiotensin receptor blocker } & 0 & Reference & & Reference & \\
\hline & $>0 \%-35 \%$ & 4.28 & (4.20 to 4.36$)$ & 4.60 & (4.51 to 4.70$)$ \\
\hline & $35 \%-70 \%$ & 5.33 & (5.22 to 5.44$)$ & 5.67 & (5.54 to 5.80$)$ \\
\hline & $70 \%-100 \%$ & 5.20 & (5.06 to 5.34$)$ & 5.50 & (5.34 to 5.67 ) \\
\hline
\end{tabular}

practices in the top 10 and 100 highest prescribers of high-cost drugs, for each of the four classes of drug; and the percentage of all prescriptions that are for highcost drugs in the top 10 and top 100 highest prescribers of high-cost drugs. For all classes of drug, except PPIs, dispensing practices appear to be over-represented among the highest prescribers of high-cost drugs.

The cost savings for the NHS in England that would accrue if dispensing practices prescribed drugs with the same prices as non-dispensing practices are presented in table 6 , with savings per month and savings per year for each class. Total cost savings available are $£ 628875$ per month or $£ 7546497$ per year, which represents $2.04 \%$ of total expenditure on these classes of drug.

\section{DISCUSSION}

\section{Summary}

We found that doctors in England rarely prescribe highcost drugs where there are equally effective low-cost alternatives, but that doctors with a potential financial conflict of interest through working in a dispensing practice are significantly more likely to prescribe high-cost options, for four commonly prescribed classes of drug. Total cost savings available, if doctors in dispensing practices were to prescribe drugs at the same price as doctors in non-dispensing practices, are $£ 7546502$ per year.

\section{Strengths and weaknesses}

This is the first contemporary study of conflict of interest in English doctors' prescribing decisions. It is also the largest study to date of dispensing practices' prescribing behaviour, by several orders of magnitude, both in terms of a number of prescribing decisions and the number of practices covered; it is also the first to use chemical and presentation-level data.

A key strength of our study design is the ability to control for confounding caused by different populations covered by each class of practice. There are good grounds to believe that the patient population covered by dispensing

Table 4 Mean cost per dose by category of dispensing practice

\begin{tabular}{|c|c|c|c|c|}
\hline & \multicolumn{4}{|c|}{ Mean cost per dose in pence $(95 \% \mathrm{Cl})$} \\
\hline & 0 dispensing patients & $\begin{array}{l}>0 \%-35 \% \text { dispensing } \\
\text { patients }\end{array}$ & $\begin{array}{l}35 \%-70 \% \text { dispensing } \\
\text { patients }\end{array}$ & $\begin{array}{l}70 \%-100 \% \text { dispensing } \\
\text { patients }\end{array}$ \\
\hline Proton pump inhibitor & 5.46 (5.44 to 5.49$)$ & 5.47 (5.41 to 5.53$)$ & 5.61 (5.53 to 5.68$)$ & 5.69 (5.57 to 5.8$)$ \\
\hline ACE inhibitor & 4.24 (4.23 to 4.25$)$ & 4.30 (4.17 to 4.43$)$ & $4.29(4.18$ to 4.4$)$ & $4.30(4.11$ to 4.49$)$ \\
\hline
\end{tabular}


Table 5 Proportion of dispensing practices in the top 10 and top 100 highest prescribers of high-cost drugs in each category

\begin{tabular}{|c|c|c|c|c|c|c|}
\hline Class & $\begin{array}{l}\% \text { dispensing } \\
\text { practices in } \\
\text { top } 10\end{array}$ & $\begin{array}{l}\% \text { dispensing } \\
\text { practices in } \\
\text { top } 100\end{array}$ & $\begin{array}{l}\% \text { dispensing } \\
\text { practices } \\
\text { nationally }\end{array}$ & $\begin{array}{l}\text { Mean \% high } \\
\text { cost in top } 10\end{array}$ & $\begin{array}{l}\text { Mean } \% \text { high } \\
\text { cost in top } 100\end{array}$ & $\begin{array}{l}\text { Mean \% } \\
\text { high cost in } \\
\text { England }\end{array}$ \\
\hline Statins & 80 & 56 & 13 & 40.79 & 17.45 & 3.04 \\
\hline Proton pump inhibitor & 10 & 11 & 13 & 33.97 & 11.73 & 1.48 \\
\hline ACE inhibitor & 90 & 29 & 13 & 33.54 & 6.98 & 0.29 \\
\hline Angiotensin receptor blocker & 100 & 86 & 13 & 81.42 & 54.64 & 3.90 \\
\hline
\end{tabular}

practices, which is predominantly rural, may be systematically different to non-dispensing practices with respect to social class, smoking, age, and other demographic and health measures. By examining prescriptions of high-cost branded drugs as a proportion of total prescriptions for that class of drug, the design of our study accounts for any confounding caused by the differential need for a given drug class in areas covered by dispensing or non-dispensing practices. We additionally adjusted for factors such as deprivation score and practice size to ensure they were not responsible for confounding, and found the multivariable results to be extremely similar. There are no a priori reasons to believe that any supposed clinical need for higher cost options for these four classes of drug is differentially distributed between dispensing and non-dispensing practice catchment areas.

One weakness of our study is that the members of each prespecified list of high-cost and low-cost options created for the logistic regression could be contested. However, the finding that the overall mean cost per dose in each drug class is higher in dispensing practices is not dependent on these choices; and we have shared all analytical code, data and lists of drug identifiers, so that others can perform their own sensitivity analyses with alternative lists of drugs should they wish. Another weakness is that, given the cross-sectional design of the study, we are unable to determine a causal relationship.

\section{Context of other work}

Previous work on smaller cohorts in different settings has found that doctors working in dispensing practices have different prescribing behaviours to those in non-dispensing settings. ${ }^{5}$ For example, a 2002 study of 57 doctors in Zimbabwe ${ }^{16}$ found that dispensing doctors prescribed more drugs per patient, injected more patients and prescribed more antibiotics, with no difference in use of generics; in South Korea a range of regulatory changes in 2000, including greater separation of pharmacists' and doctors' roles, was associated with a reduction in prescriptions for peptic ulcer drugs ${ }^{17}$ and antibiotics. ${ }^{18}$ Recent work has been more limited. An Australian study from 2011 examined the only total number of prescriptions issued, in 2005-2007 data, and found that dispensing doctors issued fewer prescriptions per 1000 patients. ${ }^{19}$ The three UK studies to date were all small and undertaken two decades ago. One examining 108 practices in Lincolnshire found higher prescribing costs and fewer prescriptions for generics in dispensing practices $^{20}$; a follow-up study in the same cohort after the introduction of target prescribing budgets reported similar findings ${ }^{21}$; and a final study in the same region (with the highest density of dispensing practices in the country) examined prescription of drugs available over the counter, ${ }^{22}$ finding they were again more commonly prescribed in dispensing practices.

These papers were criticised for failing to make adequate adjustment for the fact that dispensing practices in rural areas may see different patients to urban practices; that dispensing practices may be required to deliver different services such as vaccination (which at the time was often not delivered in general practice); and that doctors might prescribe over-the-counter drugs more commonly in areas with no pharmacy for patients' practical convenience. Our study design addresses these shortcomings. Furthermore, over the past two decades, there have been numerous developments which might affect prescribing behaviour including the new GP contract, the end of GP fundholding,

Table 6 Modelled savings per month in England if dispensing practices prescribed drugs with the same prices as nondispensing practices

\begin{tabular}{|c|c|c|c|c|}
\hline Drug class & Savings per month & Savings per year & $\begin{array}{l}\text { Total annual National } \\
\text { Health Service England } \\
\text { spend on this class }\end{array}$ & $\%$ possible savings \\
\hline Statins & $£ 276248.37$ & $£ 3314980.44$ & $£ 140314432$ & 2.36 \\
\hline Proton pump inhibitor & $£ 33448.80$ & $£ 401385.60$ & $£ 107035456$ & 0.38 \\
\hline Angiotensin receptor blocker & $£ 299194.82$ & $£ 3590337.84$ & $£ 56320168$ & 6.37 \\
\hline ACE inhibitor & $£ 19982.77$ & $£ 239793.24$ & $£ 66674248$ & 0.36 \\
\hline Total & $£ 628874.76$ & $£ 7546497.12$ & $£ 370344304$ & 2.04 \\
\hline
\end{tabular}


changes in clinical evidence and the formation of the National Institute for Health and Care Excellence. There has also been extensive patent expiry and subsequent dramatic cost reductions for many commonly prescribed classes of drug, including PPIs, ARBs, ACEi and statins.

Lastly, in the grey literature, a recent analysis by the Dispensing Doctors Association reports that the overall cost of drugs supplied per patient from English dispensing practices was less than that for prescriptions dispensed in pharmacies. ${ }^{23}$ However, this analysis uses a crude metric, makes no attempt to correct for confounders, does not apply the widely used Age, Sex and Temporary Resident Prescribing $\mathrm{Unit}^{24}$ as a patient denominator and is produced by the lobbying body for dispensing practices.

In the broader context of financial incentive and doctors' clinical activity, the current Cochrane overview of reviews evaluating the effectiveness of financial incentives in changing healthcare professionals' behaviours finds that overall such incentives are commonly effective. ${ }^{25}$ A negative impact from a perverse incentive is therefore plausible.

\section{Meaning and policy implications}

We have identified clear evidence that many doctors are responding to a financial conflict of interest. This has important implications more broadly than for dispensing practices, as it demonstrates that clinical decision-making may not be solely driven by patient need, and that unwarranted variation in care may be partly driven by financial factors for the doctor. It may also have safety implications, since newer drugs with no clear evidence of superior clinical benefit are likely to be used less frequently, and so have less safety data, but are currently prescribed to a greater extent in dispensing practices.

We have also identified significantly higher costs associated with dispensing practices, with a total of $£ 7546$ 502 per year in England across these four classes of drug, $2.04 \%$ of the total national spend on them. There are likely to be additional higher costs from other classes of drug. It may be argued that this is not avoidable waste, on the grounds that dispensing practices need this additional income in order to meet the higher costs associated with providing dispensing services in areas with a low population density. However, since most dispensing practices have not leveraged this opportunity for additional revenue, that seems unlikely; it is more likely that this is additional income for a small number of practices who have identified and acted on a financial opportunity in NHS systems for reimbursement of prescribing costs.

The NHS currently spends $£ 13$ billion per year on prescribed medication, representing over $10 \%$ of the total NHS budget. Much of this is amenable to efficiency savings. ${ }^{26}$ We believe that better monitoring of prescribing behaviour would allow easier identification of outliers on cost, effectiveness and safety, and that more robust action, when presented with outliers is likely to reduce costs and improve clinically effective prescribing. Some formularies may wish to restrict the use of very high-cost items.

\section{Future research}

We have recently received funding for a series of low-cost randomised trials assessing whether open audit and feedback on individual practices' prescribing data changes prescribing practice. We strongly suggest that existing processes to identify and address problematic prescribing behaviour should be reviewed, with their costs and evidence base assessed.

\section{Author affiliations}

${ }^{1}$ The DataLab, Nuffield Department of Primary Care Health Sciences, University of Oxford, Primary Care Health Sciences, Oxford, UK

${ }^{2}$ National Heart and Lung Institute, Imperial College London, London, UK

${ }^{3}$ Institute for Global Health, London, UK

${ }^{4}$ Epidemiology and Population Health, London School of Hygiene and Tropical Medicine, London, UK

Acknowledgements We are grateful to Richard Stevens and Rafael Perera-Salazar for statistical input into the design of the regression model, and Peter Brindle for discussions and support on the project.

Contributors BG, CR and TAY conceived and designed the study. RC created the lists of high-cost and low-cost drugs used for each query. AP-S obtained, merged and cut the data before analysis. BG conducted the analysis with input from AJW, LS, TAY and CR. AP-S replicated the analysis in IPython. BG drafted the paper, all authors contributed substantial revisions. BG acts as guarantor.

Funding This work was supported by The Health Foundation (grant number 7599).

Competing interests BG, AP-S and CR have produced free open websites offering insights into NHS prescribing data. BG receives income from speaking and writing for lay audiences on problems in science and medicine, including financial conflict of interest, but not dispensing practices or prescribing data. BG and AP-S have received funding from West of England Academic Health Sciences Network, the Health Foundation and NHS England for work on UK prescribing data. BG has received funding from the Wellcome Trust and the Laura and John Arnold Foundation to work on better use of data in medicine. TAY has worked on studies that received support from Pasante, GSK and Sanofi but has not financially benefited from this support. RC is employed by a CCG to optimise prescribing including minimising use of the high-cost items analysed here, and has received income as a paid member of advisory boards for Galen Pharmaceuticals Martindale Pharma, Galderma (UK), ProStraken Group, Menarini Farmaceutica Internazionale SRL and Stirling Anglian Pharmaceuticals. BG, CR, TAY and RC have all been employed by the NHS for a large part of their career.

Patient consent This study exclusively uses aggregated, publicly available data and therefore does not require patient consent.

Provenance and peer review Not commissioned; externally peer reviewed.

Data sharing statement Raw data can be accessed from NHS Digital. Stata code for statistical analysis, Python code for data extraction, data and code lists to identify drugs, are all available as online supplementary material on Figshare (https://doi.org/10.6084/m9.figshare.6510260).

Open access This is an open access article distributed in accordance with the Creative Commons Attribution Non Commercial (CC BY-NC 4.0) license, which permits others to distribute, remix, adapt, build upon this work non-commercially, and license their derivative works on different terms, provided the original work is properly cited, appropriate credit is given, any changes made indicated, and the use is non-commercial. See: http://creativecommons.org/licenses/by-nc/4.0/.

\section{REFERENCES}

1. Dispensing Doctors Association. Dispensing Guide. 2014 http:// www.dispensingdoctor.org/wp-content/uploads/2014/10/ DDADispensingGuide-WEB.pdf (accessed 15 Jul 2015).

2. Kassirer JP. On the Take: How Medicine's Complicity with Big Business Can Endanger Your Health. 1st ed. USA: Oxford University Press, 2004.

3. Spurling GK, Mansfield PR, Montgomery BD, et al. Information from pharmaceutical companies and the quality, quantity, and 
cost of physicians' prescribing: a systematic review. PLoS Med 2010;7:e1000352.

4. Lundh A, Sismondo S, Lexchin J, et al. Industry sponsorship and research outcome. Cochrane Database Syst Rev 2012;12:MR000033.

5. Lim D, Emery J, Lewis J, et al. A systematic review of the literature comparing the practices of dispensing and non-dispensing doctors. Health Policy 2009;92:1-9.

6. HSCIC 1 Trevelyan Square. Prescribing by GP practice. 2012 http:// www.hscic.gov.uk/gpprescribingdata (accessed 15 Feb 2016).

7. Google. Bigquery - analytics data warehouse. Google Cloud Platf. https://cloud.google.com/bigquery/ (accessed 28 Apr 2016).

8. NHS BSA. Practice List Size and GP Count for each Practice. 2016 http://www.nhsbsa.nhs.uk/PrescriptionServices/5036.aspx (accessed 28 Apr 2016).

9. Heran BS, Wong MM, Heran IK, et al. The Cochrane CollaborationBlood pressure lowering efficacy of angiotensin converting enzyme (ACE) inhibitors for primary hypertension: In. , ed. Cochrane Database of Systematic Reviews. Chichester, UK: John Wiley \& Sons, Ltd, 2008. http://doi. wiley.com/ (accessed 28 Apr 2016).

10. NICE. Hypertension in adults: diagnosis and management. https:// www.nice.org.uk/guidance/cg127 (accessed 28 Apr 2016).

11. NICE. Cardiovascular disease: risk assessment and reduction, including lipid modification | Guidance and guidelines | NICE. 2015. https://www.nice.org.uk/guidance/cg181 (accessed 28 Apr 2016).

12. McCormack T, Krause T, O'Flynn N, O'Flynn N. Management of hypertension in adults in primary care: NICE guideline. $\mathrm{Br} J \mathrm{Gen}$ Pract 2012;62:163-4.

13. Duerden MG, Hughes DA. Generic and therapeutic substitutions in the UK: are they a good thing? Br J Clin Pharmacol 2010;70:335-41.

14. Powell-Smith A. Jupyter notebooks for paper on dispensing practices and high-cost drugs. EBM DataLab GitHub. 2016. https:// github.com/ebmdatalab/dispensing_highcost_paper (accessed 8 Nov 2016).

15. StataCorp. Stata Statistical Software: Release 14. College Station, TX: StataCorp LP, 2015.
16. Trap B, Hansen EH, Hogerzeil HV. Prescription habits of dispensing and non-dispensing doctors in Zimbabwe. Health Policy Plan 2002;17:288-95.

17. Lee EK, Malone DC. Comparison of peptic-ulcer drug use and expenditures before and after the implementation of a government policy to separate prescribing and dispensing practices in South Korea. Clin Ther 2003;25:578-92.

18. Park S, Soumerai SB, Adams AS, et al. Antibiotic use following a Korean national policy to prohibit medication dispensing by physicians. Health Policy Plan 2005;20:302-9.

19. Lim D, Emery JD, Lewis J, et al. Australian dispensing doctors' prescribing: quantitative and qualitative analysis. Med J Aust 2011;195:172-5 https://www.mja.com.au/journal/2011/195/4/ australian-dispensing-doctors-prescribing-quantitative-andqualitative-analysis.

20. Morton-Jones TJ, Pringle MA. Prescribing costs in dispensing practices. BMJ 1993;306:1244-6.

21. Baines DL, Tolley KH, Whynes DK. The costs of prescribing in dispensing practices. J Clin Pharm Ther 1996;21:343-8.

22. Baines DL, Whynes DK. Over-the-counter drugs and prescribing in general practice. Br J Gen Pract 1997;47:221-4.

23. Dispensing Doctors Association. Dispensing GPs cheaper by $£ 6+$ per patient. DDA - Dispens. Dr. Assoc. 2016. http://www. dispensingdoctor.org/news/dispensing-gps-cheaper-by-6-perpatient/ (accessed 16 Mar 2016).

24. Baines D, Whynes D. The use of the ASTRO-PU and the ASTRO(97)$\mathrm{PU}$ in the setting of prescribing budgets in English general practice. $J$ Clin Pharm Ther 1998;23:229-34.

25. Flodgren G, Eccles MP, Shepperd S, et al. An overview of reviews evaluating the effectiveness of financial incentives in changing healthcare professional behaviours and patient outcomes. Cochrane Database Syst Rev 2011:CD009255.

26. Moon JC, Flett AS, Godman BB, et al. Getting better value from the NHS drug budget. BMJ 2010;341:c6449. 